\title{
An Overview of Microwave UWB Antenna for Structural Health Monitoring of Wind Turbine Blades: Optimal Design and Analysis
}

\author{
Pachiyaannan Muthusamy ${ }^{1 *}$, Prasanna Venkatesan Durairaj ${ }^{2}$ \\ ${ }^{1}$ Advanced RF Microwave and Wireless Communication Laboratory, Vignan's Foundation for Science, Technology \& \\ Research (Deemed to be University), Guntur, Andhra Pradesh, India \\ ${ }^{2}$ Dean Engineering Karpagam Academy of Higher Education (Deemed to be University), Coimbatore, Tamilnadu, India
}

Corresponding Author Email: pachiphd@gmail.com

https://doi.org/10.18280/i2m.180112

Received: 18 December 2018

Accepted: 4 February 2019

\section{Keywords:}

low profile, rectangular slot, microwave, UWB antenna, structural health monitoring, wind turbine blade

\begin{abstract}
In this research paper, a multi-slot rectangular shape with a compact size of $18 \times 10 \mathrm{~mm}$ microwave UWB antenna for structural health monitoring of wind turbine blades is presented. The objective of microwave UWB antenna to measure defects in the wind turbine blades. In this work reported an ideal outline of 9.2 to $21.4 \mathrm{GHz}$ with wider bandwidth of $12.2 \mathrm{GHz}$ is enveloping the upper band of microwave UWB frequency. The low cost RT/Duroid 5880 substrate material with dielectric constant of 0.0004 is assembled and tested. A comparative experimental method is carried out to execute the required resonance frequency by using high frequency structural 3D simulator (HFSS) tool. The proposed UWB antenna is simulated different feed position to acquire the required bandwidth and result shows that moderate peak gain and peak directivity of $3.79 \mathrm{dBi}$ and $3.63 \mathrm{dBi}$. The dispersion characteristics is simulated and occurred throughout the upper band of UWB and show that omni-directional pattern also compared proposed antenna with existing antenna. This low profile nature and compact size microwave UWB antenna behavior is best suited for structural health monitoring of wind turbine blades and flexible for wind mill monitoring system.
\end{abstract}

\section{INTRODUCTION}

Nowadays the structural health monitoring is most necessary for heavy electrical industries, civil, marine and automation industries. In daily life thousands of sensors and communication device linking together to report their equipment information in engineering environment especially the wind turbine blade performance analyzing is difficult for researchers and engineers. There is many equipment is involving during production period, maintain the quality, minimize the cost, number wire transmission and replacement of material is challenging for structural health monitoring [12] and in this way the microwave UWB antenna is introduced in this paper to monitor the turbine blade performance. The regular UWB spectrum from 3.1 to $10 \mathrm{GHz}$ is commercially available bandwidth for regular communication with higher data rate up to $20 \mathrm{mbps}$ but the multipath environment condition the microwave UWB spectrum from 9 to $22 \mathrm{GHz}$ is very much required for intra-vehicle monitoring. In [3] author reported dipole antenna for identifying material damage and its location remotely. In [4] author reported a $22 \times 22 \mathrm{~mm}$ size ladder-shaped monopole antenna is designed with bandwidth of $19.3 \mathrm{GHz}$ which is compact nature and wider bandwidth characteristics. The $30 \times 30 \mathrm{~mm}$ size hexagonal shape wideslot antenna with UWB characteristics from $2.9 \mathrm{GHz}$ to 18 $\mathrm{GHz}$ is reported in [5] which is highly wider bandwidth and required for modern communication. Another work [6] discusses about $2.54 \mathrm{GHz}$ to $21.08 \mathrm{GHz}$ printed type circular ring antenna with dimensions of $39 \times 40 \mathrm{~mm}$ which is moderate size and less return loss. The enhanced bandwidth of UWB antenna as discussed by Chia Ping Lee [7] report that the $15 \times 14.5 \mathrm{~mm}$ size antenna operated from $3.28 \mathrm{GHz}$ to 19.64 $\mathrm{GHz}$ with fractional bandwidth of $120.68 \%$. A widerbandwidth antenna from $3.9 \mathrm{GHz}$ to $22.5 \mathrm{GHz}$ is introduced in [8]. It has $25 \times 15 \mathrm{~mm}$ size and gain of $4.48 \mathrm{dBi}$ with different slot structure. Another work the author [9] signifies an antenna with dimensions of $16 \mathrm{~mm} \times 12 \mathrm{~mm} \times 0.787 \mathrm{~mm}$ size having good impedance and operated from $6.5 \mathrm{GHz}$ to $25 \mathrm{GHz}$ which is covers the entire UWB. This projected antenna having gain about $2.5 \mathrm{dBi}$ at the frequency from $6 \mathrm{GHz}$ to $22 \mathrm{GHz}$. In microwave sensing application the proposed antenna size is $19.36 \times 27.72 \mathrm{~mm}$ with BW of $3.10-15.00 \mathrm{GHz}$. The electrical dimension is $0.20 \lambda \times 0.29 \lambda$ and FBW is $131.50 \%$. This antenna represents a good fractional bandwidth when compared with previous designed antennas reported in literature [10-11] which explains the tapered-shaped slot antenna with area of $12 \times 38 \mathrm{~mm}$ another author reported [12] $9.8 \mathrm{GHz}$ to $22 \mathrm{GHz}$ UWB antenna for UWB applications. In literature [13-14] discussed the various fractal iterative shapes antenna to increase the bandwidth for UWB applications with minimal size $16 \times 12 \mathrm{~mm}$ size and bandwidth of $12.2 \mathrm{GHz}$. From the above discussion, the necessity of UWB antenna and the electrical dimension, gain and directivity of different antenna were studied. In this research paper, the proposed antenna achieved upper band UWB frequency with dimension of $18 \mathrm{x}$ $10 \mathrm{~mm}$ size which is very compact compared the above literature also having low profile nature, moderate gain, omnidirectional radiation pattern and good directivity. The overall radiation pattern is good compared to existing antenna. 


\section{SCOPE OF THE PAPER}

From reference to the study and examination completed, the proposed antenna is created to improvise the scaling component and arrangement. In this examination the accompanying reproduction result are accomplished:

(1). The proposed UWB antenna radiation size is $18 \times 10 \mathrm{~mm}$ and ground structure size is $20 \times 11 \mathrm{~mm}$.

(2). The first harmonic of $9.6 \mathrm{GHz}$ exhibit a bandwidth of $800 \mathrm{MHz}$ on the lower band and VSWR is 1.169 , the higher band of $20.8 \mathrm{GHz}$ exhibit at a bandwidth of $1800 \mathrm{MHz}$ and VSWR value is 0.44 .

(3). At second harmonic of $11.3 \mathrm{GHz}$ exhibit at a bandwidth of $700 \mathrm{MHz}$ and VSWR value is 0.127

(4). The third and fourth harmonic of 16 and $18 \mathrm{GHz}$ frequency exhibit at a bandwidth of $600 \mathrm{MHz}$ and $1200 \mathrm{MHz}$.

(5). Achieved omni directional radiation pattern with uniform dispersion characteristics.

(6). The proposed antenna radiation efficiency, peak gain and peak directivity is achieved at the rate of $96.6 \%, 3.79 \mathrm{dBi}$ and $3.63 \mathrm{dBi}$. The following sections will discuss about the antenna design and analyse the performance of reference antennas. In further Section 3 reported about antenna modelling and design and structure issues and Section 4 reported the comparative study of different reference antennas to achieve the required resonant frequency finally the Section 5 discusses the antenna simulation and measurements results and Section 6 concludes the paper with applications.

\section{ANTENNA MODELLING AND DESIGN}

The estimated geometry structure of proposed UWB antenna is shown in Figure. 1 and Figure. 2 with layout of coaxial probe-feeding. It is constructed by Duroid5880 high frequency laminate substrate material with a relative permittivity of 2.22 and loss tangent of 0.0004 . This high frequency substrate fed by a micro strip line $50 \Omega$ with diameter of $0.8 \mathrm{~mm}$ and feed position of coaxial system determine the impedance matching so in this proposed design the input resistance, conductance and feed reactance value calculated. The dimension of ground plane and radiation plane size is $20 \times 11 \mathrm{~mm}$ and $18 \times 10 \mathrm{~mm}$ size and is placed in 3D plane axis. The detailed antenna dimension is shown in Table 1.

The proposed antenna exhibits tri-band characteristics i.e., operated at X-band, Ku-band and K-bands. To match the impedance matching and improve the wide band behaviour coaxial feed is used. Based on the substrate material characteristics like permittivity and loss tangent value the antenna resonant frequency and bandwidth define. In Table. 2 shows that different substrate material properties, it understand that Duroid5880 having low dielectric constant which is prove that to increase the bandwidth and good impedance matching for high frequency application. Duroid5880 has been used in circuitry for commercial wireless, mobile network and medical applications. For these reasons the Duroid5880 substrate material was referred for proposed work to attain the required band. To improve the attenuation loss and power factor the proposed design is used $50 \Omega$ coaxial feed. The characteristics impedance is necessary to match the input resistance and it's based on the feed position of coaxial feed
Table 1. Proposed antenna dimension in $\mathrm{mm}$

\begin{tabular}{cccccccc}
\hline $\begin{array}{c}\text { Parameter in } \\
\text { mm }\end{array}$ & W1 & W2 & W3 & W4 & W5 & W6 & W7 \\
\hline $\begin{array}{c}\text { Antenna } \\
\text { dimension }\end{array}$ & 1.25 & 1 & 1.12 & 1.5 & 1.8 & 1.12 & 1 \\
$\begin{array}{c}\text { Parameter in } \\
\text { mm }\end{array}$ & L1 & L2 & L3 & L4 & L5 & L6 & L7 \\
$\begin{array}{c}\text { Antenna } \\
\text { dimension }\end{array}$ & 12.75 & 8.5 & 10 & 9 & 9.75 & 6.5 & 4.5 \\
$\begin{array}{c}\text { Parameter in } \\
\text { mm }\end{array}$ & L8 & L9 & L10 & Lg & Wg & - & - \\
$\begin{array}{c}\text { Antenna } \\
\text { dimension }\end{array}$ & 7 & 8.14 & 6 & 20 & 11 & - & - \\
\hline
\end{tabular}

Table 2. Dielectric properties of different substrate materials

\begin{tabular}{ccc}
\hline Material & Permittivity & Loss tangent \\
\hline Duroid 5880 & 2.22 & 0.0004 \\
Duroid 5870 & 2.33 & 0.0023 \\
FR4 & 4.66 & 0.020 \\
Bakelite & 4.78 & 0.03045 \\
RO4003 & 3.4 & 0.002 \\
Taconic TLC & 3.2 & 0.002 \\
\hline
\end{tabular}

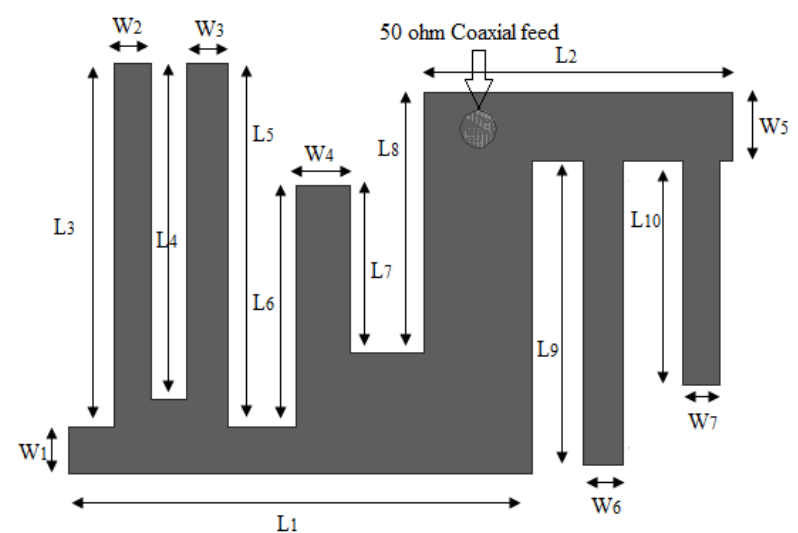

Figure 1. The Proposed UWB antenna design layout

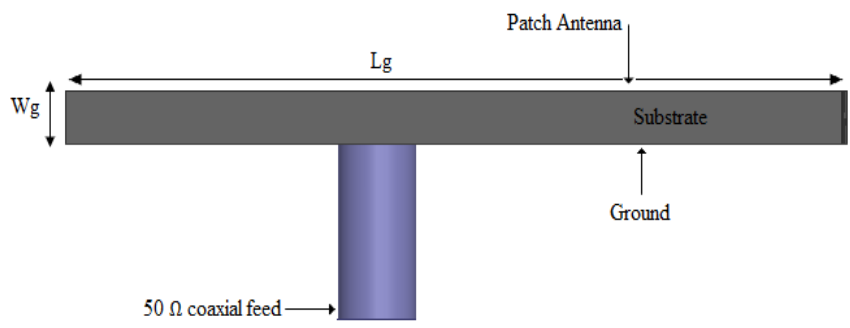

Figure 2. The proposed UWB antenna with coaxial feed structure

The input resistance can be written as,

$R_{\text {in }}\left(\rho^{\prime}=\rho_{e}\right)=R_{\text {in }}\left(\rho^{\prime}=a_{e}\right) \frac{J_{1}^{2}\left(k \rho_{0}\right)}{J_{1}^{2}\left(k \rho_{e}\right)}$

$R_{\text {in }}\left(\rho^{\prime}=a_{e}\right)=\frac{1}{G_{t}}$ 
where, $\left(\rho^{\prime}=\rho_{e}\right)$ is the input resistance at any radial distance from the centre of the patch reported in Eq. (1) and (2). If input resistance is $50 \Omega$ the Eq. (2) becomes

$R_{\text {in }}(50)=\frac{1}{G_{t}}$

where, $\mathrm{G}_{\mathrm{t}}$ is the total conductance and can be rewritten as,

$\mathrm{G}_{\mathrm{t}}=\mathrm{G}_{\mathrm{rad}}+\mathrm{G}_{\mathrm{c}}+\mathrm{G}_{\mathrm{d}}$

The $\mathrm{G}_{\mathrm{t}}$ can be calculated by radiation, conductance and dielectric losses values. If the substrate dielectric losses value vary, the total conductance value change and finally the resonant frequency mismatch occur. When calculating resonant frequency, the impedance value should consider and include both resistances, reactance value. At $50 \Omega$ impedance the feed reactance can written as

$\mathrm{x}_{\mathrm{f}}=-\frac{\eta \mathrm{kh}}{2 \pi}\left[\ln \left(\frac{\mathrm{kd}}{4}\right)+0.577\right]$

where, $\mathrm{d}$ is the diameter of the feed probe.

The feed reactance indicates that the axis of feed position of patch antenna. If the feed position is improper the total reactance value varies and finally impedance mismatch occurs in the transmission line.

The feed position is independent of the input power but dependent on input resistance. If the feed position of the proposed design at $(7,0,0)$ scale from $\mathrm{x}, \mathrm{y}$ and $\mathrm{z}$ axis. The coaxial feed model of antenna excited by a coaxial transmission line and further improving of electric and magnetic field to applying the cartesian coordinated system the mathematical equations can be represents as an equivalent magnetic frill current. The magnetic frill current at axis $(7,0,0)$ can be written as,

$M(7,0,0)=\frac{-2 \mathrm{~V}_{\text {inc }}(t)+\mathrm{Z}_{0} \mathrm{I}(t)}{\operatorname{aln}(\mathrm{b} / \mathrm{a})}$

where, $\mathrm{M}$ is magnetic-frill current, $\mathrm{V}_{\mathrm{inc}}$ is the incident voltage, $\mathrm{I}(\mathrm{t})$ is the feed current, the characteristic impedance is denoted by $\mathrm{Z}_{0}$ for coaxial feed line and inner, outer conductor of the cable is represented by $\mathrm{a}$ and $\mathrm{b}$ in radius. In the above equations (1), (2), (3), (4) and (5) report that the impedance matching of coaxial probe feed with insert positions to achieve resonant frequencies and by using these equations to find the input resistance, reactance and total conductance value of patch antenna.

\section{COMPARATIVE STUDY AND NUMERIC RESULTS}

In this segment, the comparative study of the proposed antenna (Ant.1) was carried out with two different antennas (Ant.2, Ant.3). In Figure.3 author have analyzed Ant.1 performance level with Ant.2 and Ant.3 radiation dimensions of L4, L6 and L8 stem. The return loss and VSWR characteristics of Ant2 and Ant. 3 were investigated and the performance of the antenna (Ant.1) is verified. Therefore, the aim of the parametric study is to examine the behaviour of multi length rectangular slot L4, L6 and L8 value and how this value can achieve ultra-wideband characteristics. The prototype model of proposed antenna front view with coaxial feeding structure is display in Figure 4 (a) and Figure 4 (b). The numeric result performance of both simulation and measurement is shown in Table 3 along the reference antenna.

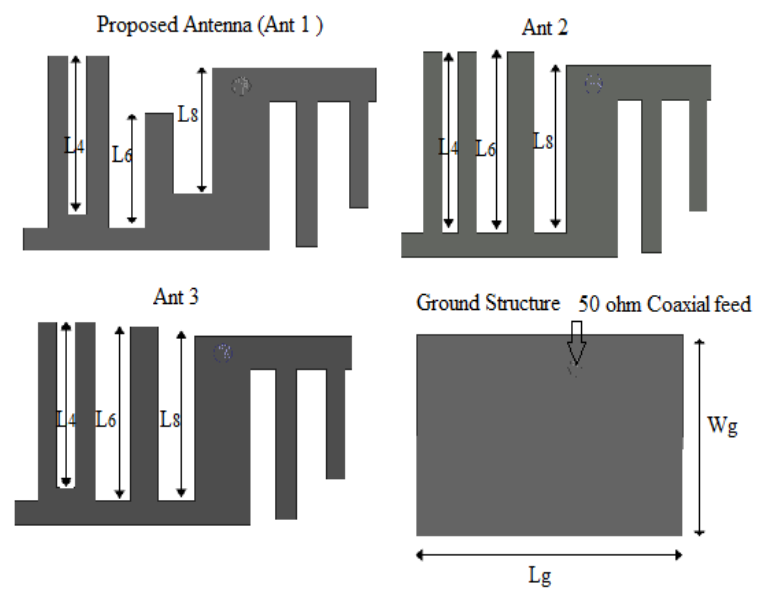

Figure 3. Geometry of proposed antenna (Ant.1), Ant.2, Ant.3 and ground Structure

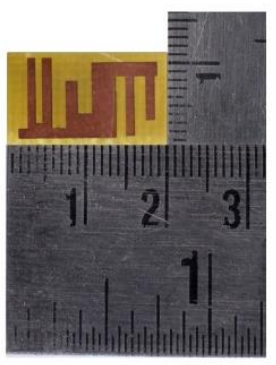

(a)

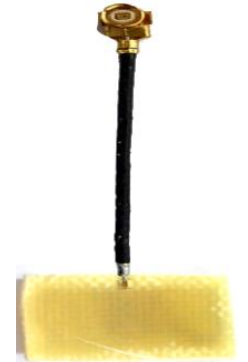

(b)
Figure 4. Prototype model of proposed UWB antenna (a) Front view with scaling (b) coaxial feeding structure

Figure 3 illustrates the parametric study used to develop the proposed UWB antenna as follows:

Step I) Geometry performance of Ant. 2 length L4=9.75 mm, L6 $=9.75 \mathrm{~mm}$ and $\mathrm{L} 8=9 \mathrm{~mm}$ with Ant. 1

Figure 3 shows that the geometry structures of proposed antenna (Ant.1) and reference antenna (Ant.2), (Ant.3) and ground plane. To vary the dimensions of L4, L6 and L8 rectangular value of Ant. 2 compare with proposed antenna (Ant.1) the resonant frequency is varied. The return loss curve and voltage standing wave ratio (VSWR) curve is shown in Figure 5 and Figure 6 also the Table 3 show that comparison of proposed antenna along with modified antenna.

Step II) Geometry performance of Ant.3 length L4=9mm, L6 $=9.5 \mathrm{~mm}$ and $\mathrm{L} 8=9 \mathrm{~mm}$ with Ant. 1 .

Figure 3 shows the Ant 3 structure. In this analysis a comparison is carried out with Ant.3 and Ant.1.The Length L4, L6 and L8 $=9 \mathrm{~mm}$ sizes vary from Ant. 1 . It was found that the first, second, third and fourth resonant frequency of Ant.3 is $11.8,13.1,16.3$ and $21.2 \mathrm{GHz}$ which is vary from Ant.1.when compared to the first resonant frequency of Ant. $19.8 \mathrm{GHz}$ not appeared in Ant. 3 because of the change of rectangular length values L4, L6 and L8. From the above discussion the Ant.1 (proposed antenna) is the best parameter for good impedance bandwidth and reflection coefficient when compared with Ant 2 and Ant 3 and also from the Table 3, its observe that simulation performance of proposed antenna (Ant1), Ant2 and 
Ant3 which shows that bandwidth, return loss and VSWR, it is observed that proposed antenna having Ultra-wideband characteristics and is having five resonant frequencies which cover entire band of microwave UWB frequency and lower band of K-band UWB frequencies.

The proposed UWB antenna with existing antenna literature survey performance report is shown in Table 4 from the above reference [4-11] were also studied and material characteristics, gain and bandwidth are discussed. To ensure that all the antennas covered UWB characteristics with different applications. Although the proposed antenna has optimal dimension $18 \times 10 \mathrm{~mm}$ size, moderate gain and wider bandwidth characteristics.

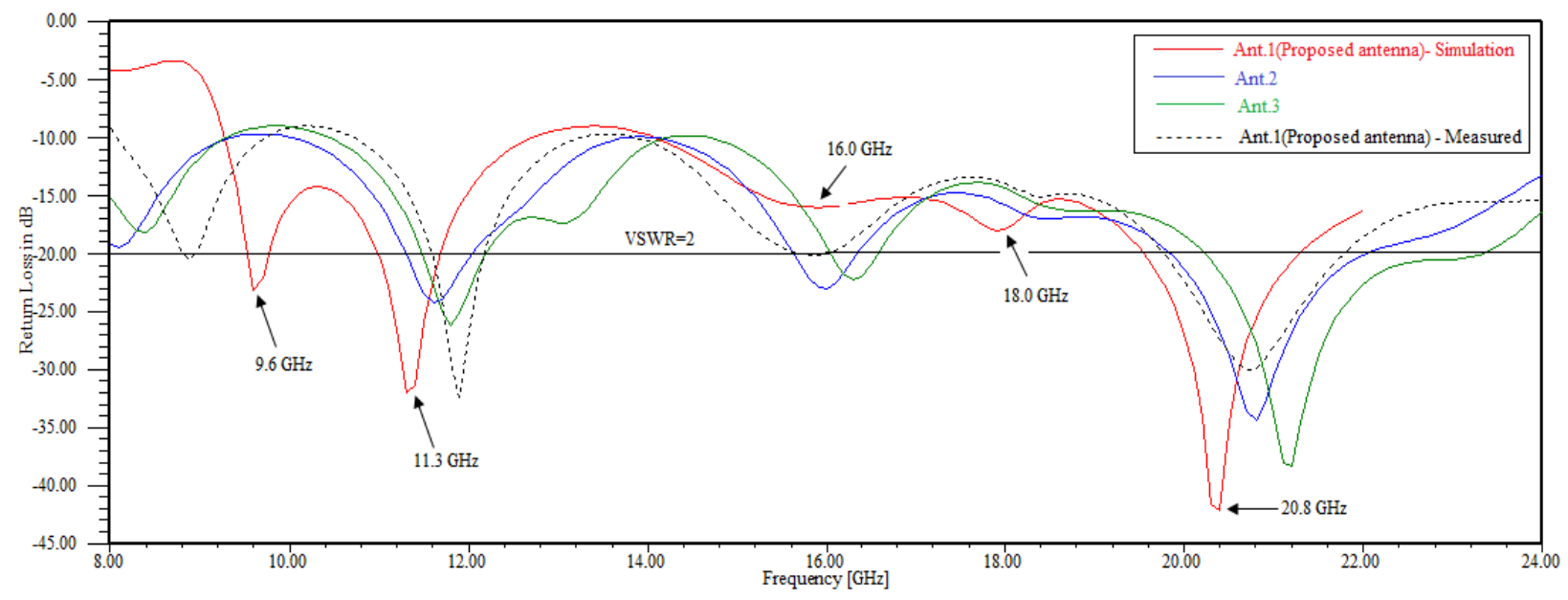

Figure 5. Measured and simulated return loss of proposed antenna (Ant.1), Ant.2, and Ant.3

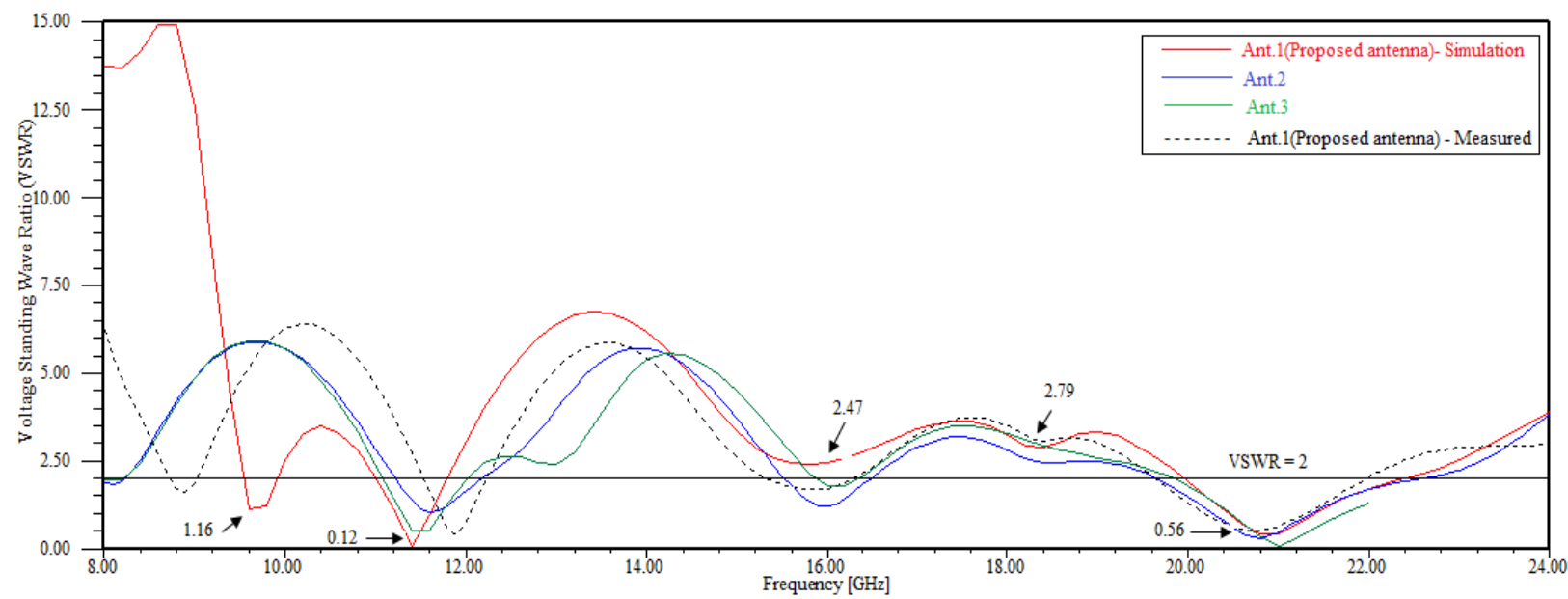

Figure 6. Measured and simulated VSWR of proposed antenna (Ant.1), Ant.2 and Ant.3

Table 3. Simulated and measured antenna characteristics for the proposed antenna (Ant.1), Ant.2 and Ant.3

\begin{tabular}{|c|c|c|c|c|}
\hline $\begin{array}{c}\text { Antenna } \\
\text { /Length of } \\
\text { Rect.slot in } \mathrm{mm}\end{array}$ & $\begin{array}{l}\text { Operating } \\
\text { Freq. } \\
\text { in } \mathrm{GHz}\end{array}$ & $\begin{array}{c}\text { Return } \\
\text { loss in } \\
\mathrm{dB}\end{array}$ & VSWR & $\begin{array}{c}\mathrm{BW}= \\
\mathrm{F}_{\text {lower }} \sim \\
\mathrm{F}_{\text {higher }} \\
\text { in } \mathrm{GHz}\end{array}$ \\
\hline Proposed & $9.6 / 8.9$ & $\begin{array}{l}-23.09 / \\
-20.52\end{array}$ & $\begin{array}{c}1.169 / \\
1.55\end{array}$ & $\begin{array}{c}9.2 \sim 10.0 \\
8.5 \sim 9.2\end{array}$ \\
\hline antenna & $11.3 / 11.7$ & $\begin{array}{l}-31.94 / \\
-29.8\end{array}$ & $\begin{array}{c}0.127 / \\
0.34\end{array}$ & $\begin{array}{c}11 \sim 11.7 / \\
11.2 \sim 12.2\end{array}$ \\
\hline (simulation)/ & $16.0 /$ & $-16.0 /$ & $2.47 /$ & $15.6 \sim 16.2 /$ \\
\hline (measured) & 16.0 & -19.54 & 1.83 & $15.4 \sim 16.4$ \\
\hline $\mathrm{L} 4=9.0 \mathrm{~mm}$, & $18.0 /$ & $-17.9 /$ & $2.79 /$ & $17.4 \sim 18.6 /$ \\
\hline $\mathrm{L} 6=6.5 \mathrm{~mm}$, & 18.1 & -16.2 & 2.96 & $18.0 \sim 18.8$ \\
\hline \multirow{2}{*}{$\mathrm{L} 8=7.0 \mathrm{~mm}$. } & $20.8 /$ & $-42.0 /$ & $0.44 /$ & $19.6 \sim 21.4$ \\
\hline & 20.5 & -31.17 & 0.48 & $19.8 \sim 21.8$ \\
\hline Ant. 2 & 11.6 & -24.2 & 1.06 & $10.9 \sim 12.7$ \\
\hline (simulation) & 16.0 & -23.02 & 1.22 & $15.6 \sim 17.0$ \\
\hline $\mathrm{L} 4=9.75 \mathrm{~mm}$ & 18.5 & -17.0 & 2.4 & $18.0 \sim 19.0$ \\
\hline $\mathrm{L} 6=9.75 \mathrm{~mm}$, & 20.8 & -34.3 & 0.33 & $20.2 \sim 21.8$ \\
\hline
\end{tabular}

\begin{tabular}{ccccc}
\hline L8 $=9.0 \mathrm{~mm}$. & & & & \\
Ant.3 & 11.8 & -26.1 & 0.85 & $11.2 \sim 12.2$ \\
(simulation) & 13.1 & -17.3 & 2.38 & $12.6 \sim 13.5$ \\
L4 $=9.0 \mathrm{~mm}$, & 16.3 & -22.2 & 1.33 & $15.9 \sim 17.2$ \\
L6 $=9.5 \mathrm{~mm}$, & & & & \\
L8 $=9.0 \mathrm{~mm}$. & 21.2 & -38.2 & 0.21 & $20.9 \sim 21.7$ \\
\hline
\end{tabular}

Table 4. Comparison of proposed UWB antenna with existing antenna

\begin{tabular}{|c|c|c|c|c|}
\hline Ref. Ant & $\begin{array}{c}\text { Size } \\
\text { in } \mathrm{mm}\end{array}$ & $\begin{array}{c}\text { Operating } \\
\text { Band in } \\
\text { GHz }\end{array}$ & $\begin{array}{c}\text { Gain in } \\
\mathrm{dBi}\end{array}$ & Application \\
\hline [4] & $22 \times 22$ & $2.7-20$ & $\begin{array}{c}\text { Not } \\
\text { reported }\end{array}$ & $\begin{array}{c}\text { Ultra- } \\
\text { Wideband }\end{array}$ \\
\hline [5] & $30 \times 30$ & $2.9-18$ & $\sim 3$ & $\begin{array}{c}\text { Ultra- } \\
\text { Wideband }\end{array}$ \\
\hline [6] & $39 \times 40$ & $2.54-21.08$ & $\sim 0$ & $\begin{array}{c}\text { Ultra- } \\
\text { Wideband }\end{array}$ \\
\hline [7] & $15 \times 14.5$ & $3.28-19.64$ & $\begin{array}{c}\text { Not } \\
\text { reported }\end{array}$ & $\begin{array}{c}\text { Ultra- } \\
\text { Wideband }\end{array}$ \\
\hline
\end{tabular}




\begin{tabular}{|c|c|c|c|c|}
\hline [8] & $25 \times 15$ & $3.95-22.5$ & 4.44 & $\begin{array}{c}\text { Ultra- } \\
\text { Wideband }\end{array}$ \\
\hline [9] & $16 \times 12$ & $6.5-25$ & 2.5 & $\begin{array}{l}\text { Ultra- } \\
\text { Wideband }\end{array}$ \\
\hline$[10]$ & $\begin{array}{c}19.36 \times \\
27.72\end{array}$ & $3.10-15.00$ & $1.2 \sim 6.57$ & $\begin{array}{c}\text { Microwave } \\
\text { Sensing }\end{array}$ \\
\hline [11] & $22 \times 24$ & $3-11.2$ & $\sim 6.5$ & $\begin{array}{c}\text { Ultra- } \\
\text { Wideband } \\
\text { Ultra - }\end{array}$ \\
\hline $\begin{array}{c}\text { Proposed } \\
\text { Work } \\
\text { (Ant.1) }\end{array}$ & $18 \times 10$ & $9.2-21.4$ & $\sim 3.93$ & $\begin{array}{l}\text { Wideband } \\
\text { Structural } \\
\text { Health } \\
\text { Monitoring }\end{array}$ \\
\hline
\end{tabular}

\section{ANTENNA RESULTS AND DISCUSSION}

In this segment, normalized radiation pattern, simulation performance of coaxial feed axis position and radiation efficiency are discussed. The Figure 7 shows that simulated radiation pattern of co-polar and cross-polar section which define how the $\mathrm{E}$ and $\mathrm{H}$ plane take place in the medium. By the way of $y-z$ axis and $x-z$ axis the $E$ and $H$ plane is defined with omni- directional pattern. It was observed that the standard radiation pattern is achieved which means that the copolarization is higher than the cross polarization for the frequencies of 9.6, 11.3, 16.0, 18.0 and $20.8 \mathrm{GHz}$ and it is exhibited better broadside radiation. This is suitable radiation patterns for higher band UWB applications.

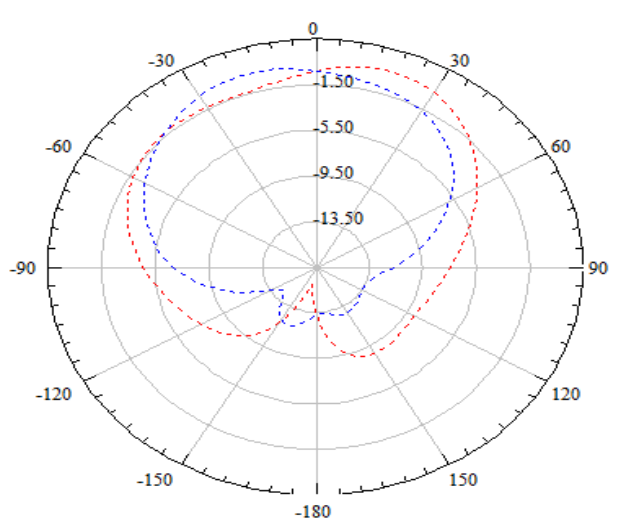

(a)

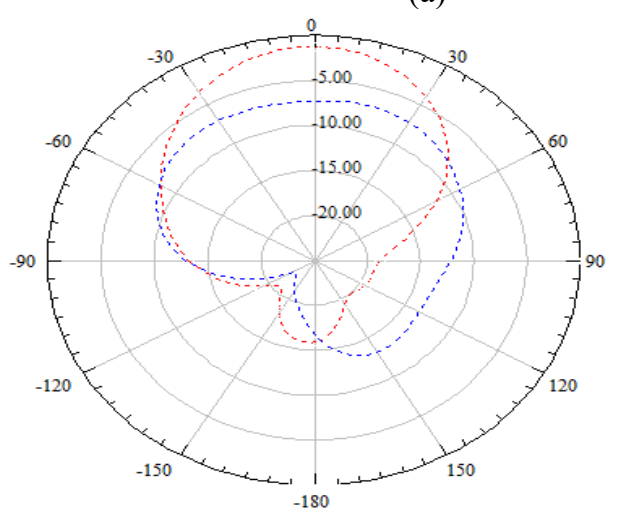

(c)

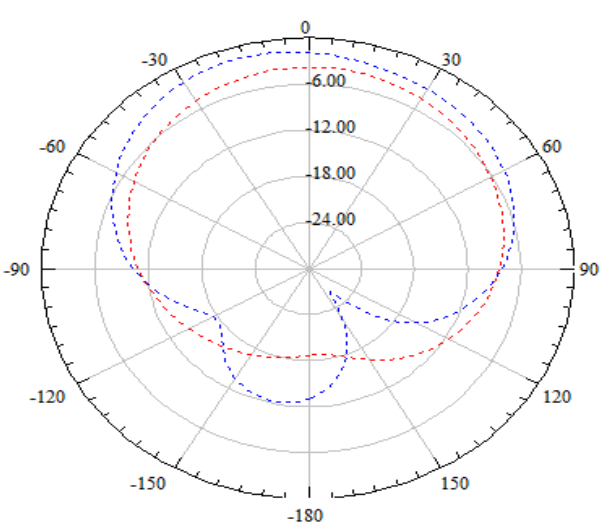

(b)

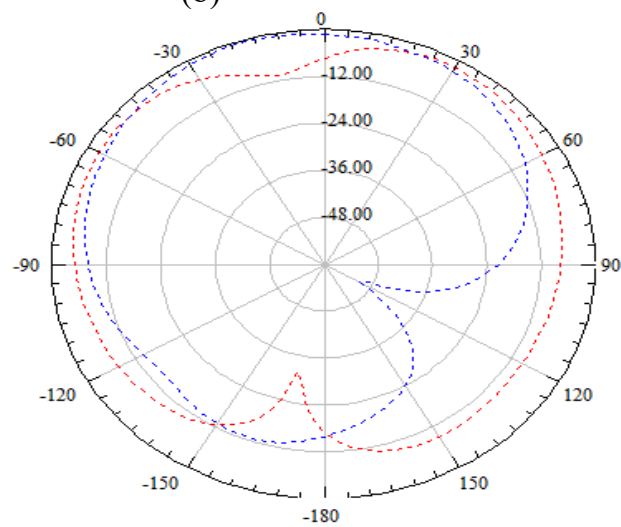

(d)

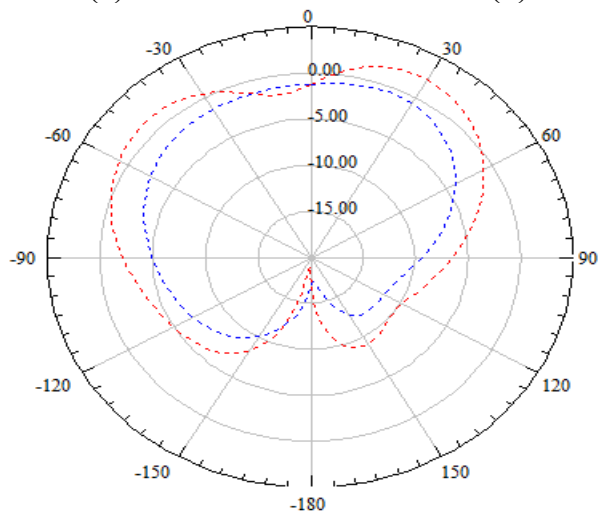

(e)

Figure 7. Simulated normalized radiation patterns at (a) 9.6, (b) 11.3 , (c) 16.0, d) 18.0, and (e) $20.8 \mathrm{GHz}$

The feed position is necessary for coaxial feed to achieve required resonant frequencies. The proposed antenna insert feed position from centre of the patch position is $(7,0,0)$ i.e., $\mathrm{x}, \mathrm{y}$ and $\mathrm{z}$ axis which is produced five resonant frequency with ultra-wide bandwidth characteristics which is shown in Figure 5. The reference antenna feed position axis $(15,0,0)$ is 
compare with proposed antenna shown in Figure. 8. When changing the insert feed position axis from $(7,0,0)$ to $(15,0$, $0)$ the total resonant frequency varied and its proved that the mismatch between the transmission lines. The Figure. 8 observed that first and fifth resonant frequency appeared with some variations and remaining resonant frequency is discarded due to that feed position axis when compare with proposed antenna design feed position axis $(7,0,0)$.

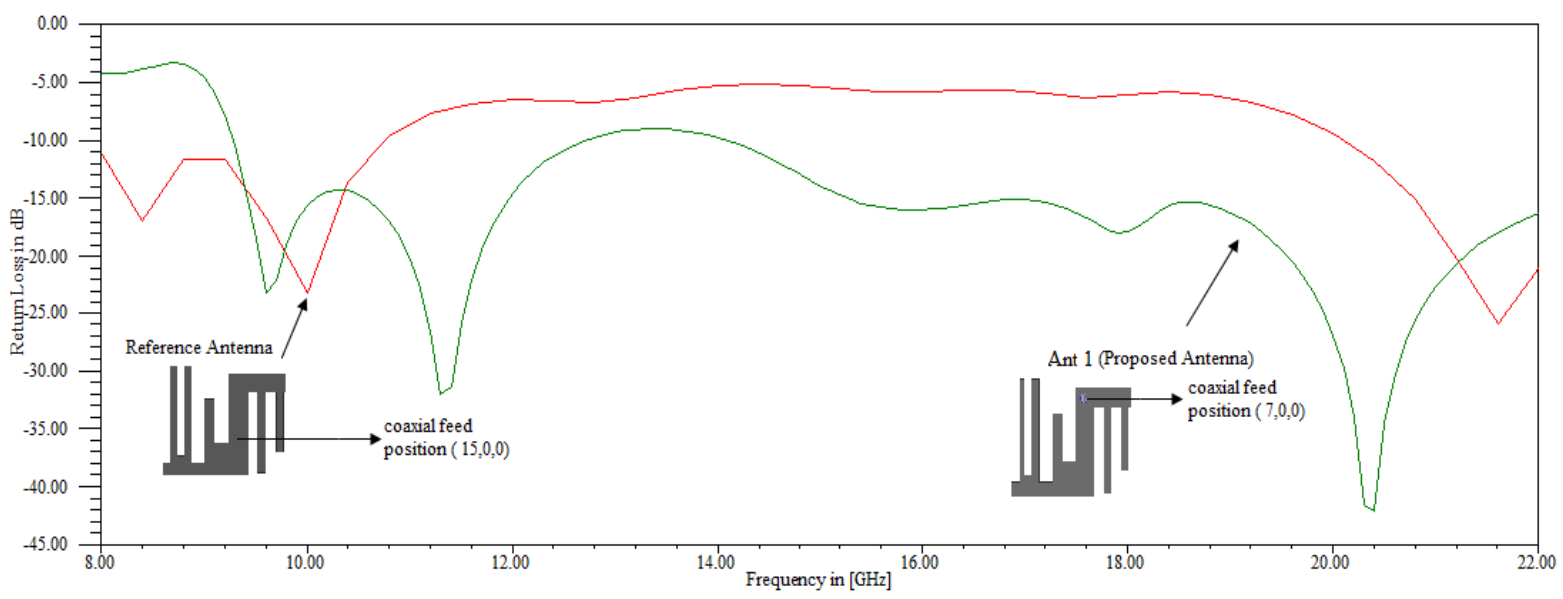

Figure 8. Simulated coaxial feed position of reference antenna with proposed UWB antenna

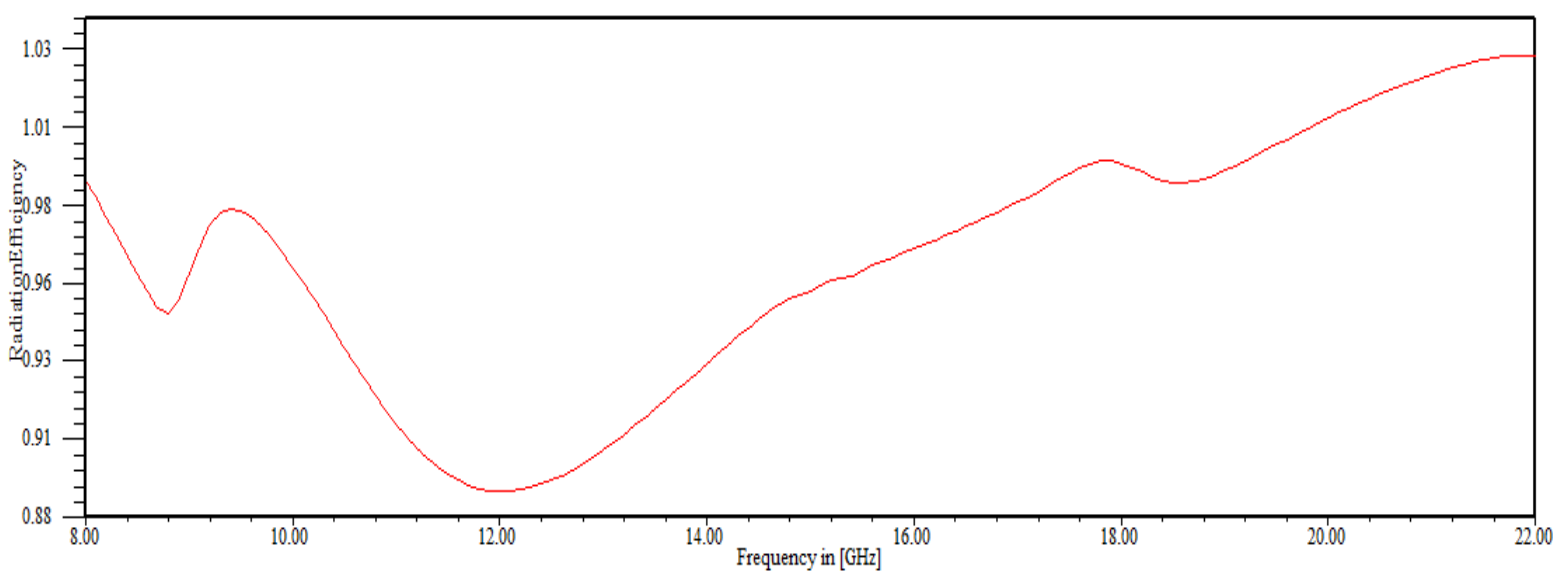

Figure 9. Radiation efficiency of proposed UWB antenna

The simulated frequency Vs radiation efficiency curve is shown in Figure 9. It shows that maximum radiation efficiency for the proposed design is $96.6 \%$. The UWB antenna cover from $89 \%$ to $100 \%$ for both lower band and higher band frequency of Microwave and K-band UWB frequency and only the middle band efficiency i.e., $16 \mathrm{GHz}$ frequency appeared $89 \%$ the remaining resonant frequency proved above $90 \%$.

Subsequently, in this research the proposed antenna has minimal size i.e., $18 \times 10 \mathrm{~mm}$ and contrasting existing antenna demonstrating that great radiation pattern and its appropriate for UWB frequencies.

\section{CONCLUSIONS}

By essentially adjusted the length of the rectangular shape in the patch the whole band of microwave UWB and lower band of K-band UWB band frequencies can be accomplished in this examination. At long last, proposed antenna with UWB attributes is effectively simulated and measured, its demonstrating a near omni-directional pattern, stable peak gain and peak directivity proficiency over the required band structure. Consequently, the advantages of basic structure, smaller size, easy to fabricate and excellent performances make this antenna a decent candidate for structural health monitoring applications. The simulated result has peak gain of $3.79 \mathrm{dBi}$ and peak directivity of $3.63 \mathrm{dBi}$ which is very much required for structural health monitoring of wind turbine blades and future with help of microwave UWB antenna to monitor multi system using single element UWB antenna also three-dimensional point tracking to measure rotating dynamics of wind turbines.

\section{REFERENCES}

[1] Chang PC, Flatau A, Liu SC. (2003). Review paper: health monitoring of civil infrastructure. Structural Health Monitoring 2(3): 257-267. http://dx.doi.org/10.1177/1475921703036169

[2] Jr BFS, Ruiz-Sandoval ME, Kurata N. (2004). Smart sensing technology: opportunities and challenges. Structural Control and Health Monitoring 11(4): 349-368. https://doi.org/10.1002/stc.48

[3] Matsuzaki AR, Melnykowycz M, Todoroki A. (2009). 
Antenna/sensor multifunctional composites for the wireless detection of damage. Composites Science and Technology 69(15-16): 2507-2513. http://dx.doi.org/10.1016/j.compscitech.2009.07.002

[4] Sheikhan RAS, Moghadasi MN, Ebadifallah E, Rousta H, Katouli M, Virdee BS. (2010). Planar monopole antenna employing back-plane ladder-shaped resonant structure for ultra-wideband performance. IET Microwaves, Antennas and Propagation 4: 1327-1335. http://dx.doi.org/10.1049/iet-map.2009.0067

[5] Ghaderi MR, Mohajeri F. (2011). A compact hexagonal wide-slot antenna with microstrip-fed monopole for UWB application. IEEE Antennas and Wireless Propagation Letter 10: 682-685. http://dx.doi.org/10.1109/LAWP.2011.2158629

[6] Azim R, Islam MT, Misran N. (2010). Printed circular ring antenna for UWB application. Proceedings of the $6^{\text {th }}$ International Conference on Electrical and Computer Engineering (ICECE'10), pp. 361-363. http://dx.doi.org/10.1109/ICELCE.2010.5700703

[7] Lee CP, Chakrabarty CK. (2011). Ultra-wideband microstrip diamond slotted patch antenna with enhanced bandwidth. Int. J. Communications, Network and System Sciences 468-474. http://dx.doi.org/10.4236/ijcns.2011.47057

[8] Nasr MA, Ouda MK, Ouda SO. (2013). Design of starshaped micro strip patch antenna for ultra-wideband. International Journal of Wireless \& Mobile Networks (IJWMN) $5(4)$
[9] Vakula RSD, Sarma NVSN. (2014). Compact concentric ring-shaped antenna for ultra-wide band applications. IOP Conf. Series: Materials Science and Engineering 67, 2nd Radio and Antenna Days of the Indian Ocean (RADIO 2014). https://doi.org/10.1088/1757899X/67/1/012004

[10] Islam MT, Islam MM, Samsuzzaman M, Faruque MRI, Misran N. (2015). A negative index metamaterialinspired UWB antenna with an integration of complementary SRR and CLS unit cells for microwave imaging sensor applications. Sensors 15: 11601-11627. https://doi.org/10.3390/s150511601

[11] Azim R, Islam MT, Misran N. (2011). Compact tapered shape slot antenna for UWB applications. IEEE Antennas and Wireless Pro.Letters 10: 1190-1193. http://dx.doi.org/10.1109/LAWP.2011.2172181

[12] Ghassemi N, Rashed-Mohassel J, Neshati MH. (2008). Slot coupled microstrip antenna for ultra wideband applications in $\mathrm{C}$ and $\mathrm{X}$ bands. Progress in Electromagnetics Research $M$ 3: 15-25. http://dx.doi.org/10.2528/PIERM08051202

[13] Xu HY, Zhang H, Yin X, Lu K. (2010). Ultra-wideband Koch fractal antenna with low back scattering cross section. Journal of Electromagnet Wave and Applications 24: 2615-2623. http://dx.doi.org/10.1163/156939310793675790

[14] Lizzia L, Azarob R, Oliveric G, Massad A. (2012). Multiband fractal antenna for wireless communication systems for emergency management. Journal of Electromagnet Wave and Applications 26: 1-11. http://dx.doi.org/10.1163/156939312798954865 